\title{
The association between clinical parameters and glaucoma-specific quality of life in Chinese primary open-angle glaucoma patients
}

\author{
Jacky WY Lee *, Catherine WS Chan, Jonathan CH Chan, Q Li, Jimmy SM Lai
}

This article was published on 28 February 2014 at www.hkmj.org.
Glaucoma Quality of Life-15 score, but did not attain statistical significance $(r=0.3, \mathrm{P}=0.07)$. There were no statistically significant correlations for the other clinical parameters with the Glaucoma Quality of Life-15 scores (all P values being $>0.7$ ). The three most problematic activities affecting quality of life were "adjusting to bright lights", "going from a light to a dark room or vice versa", and "seeing at night".

Conclusion: For Chinese primary open-angle glaucoma patients, binocular visual field index and visual acuity correlated linearly with glaucomaspecific quality of life, and activities involving dark adaptation were the most problematic. clinical measurements were correlated with Glaucoma Quality of Life-15 findings using Pearson's correlation coefficient and linear regression. The measurements were the visual field index and pattern standard deviation from the Humphrey Field Analyzer, Snellen best-corrected visual acuity, presenting intra-ocular pressure, current intra-ocular pressure, average retinal nerve fibre layer thickness via optical coherence tomography, and the number of topical anti-glaucoma medications being used.

Results: In these patients, there was a significant correlation and linear relationship between a poorer Glaucoma Quality of Life-15 score and a lower visual field index $\left(r=0.3, r^{2}=0.1, \mathrm{P}=0.01\right)$ and visual acuity $\left(r=0.3, r^{2}=0.1, \mathrm{P}=0.03\right)$. A thinner retinal nerve fibre layer also correlated with a poorer
DOI: $10.12809 / \mathrm{hkmj} 134062$

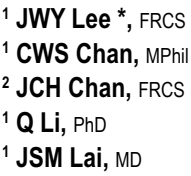

Department of Ophthalmology, The University of Hong Kong, Pokfulam, Hong Kong

2 Department of Ophthalmology, Queen Mary Hospital, Pokfulam, Hong Kong

* Corresponding author: jackywylee@gmail.com

\section{Hong Kong Med J 2014;20:274-8}

New knowledge added by this study

- A lower visual field index and poorer visual acuity correlated with a poorer glaucoma-specific quality of life in Chinese primary open-angle glaucoma patients.

- The most problematic activities affecting quality of life in glaucoma patients were "adjusting to bright lights", "going from a light to a dark room or vice versa", and "seeing at night".

Implications for clinical practice or policy

- In busy clinical settings, the visual field index serves as a quick reference for glaucoma-specific quality of life, and can identify patients who may warrant more formal assessment for psychosocial support.

- Lifestyle modifications for glaucoma patients can include more light in dark areas and adjusting curtains and mirrors to reduce glare, so as to make the transition from different lighting conditions more acceptable.

\section{Introduction}

In clinical practice, much time is spent on measuring the clinical parameters of glaucoma including the intra-ocular pressure (IOP), visual acuity (VA), visual field, and retinal nerve fibre layer (RNFL) thickness. What is often neglected is the quality of life (QOL) of patients and how well they live with their disease on a day-to-day basis. Glaucoma affects 80 million people worldwide. ${ }^{1}$ It is a chronic and irreversible disease with a heavy burden on visual function and vision, besides being one of the most important constituents affecting QOL. ${ }^{2-4}$

Recourse to QOL questionnaires in glaucoma can be broadly divided into general health-related, vision-specific, or glaucoma-specific. ${ }^{5}$ Quality-oflife assessment in glaucoma patients is as important 
as the clinical parameters used to measure glaucoma progression, because it reflects the impact of the ocular disease on the patient as a whole and may also be an indicator of whether the disease is advancing. ${ }^{4,6-9}$

Using generic QOL assessments, glaucoma was found to have deleterious impact as other systemic chronic diseases like osteoporosis, diabetes, or dementia. ${ }^{10}$ However, such generic tests do not address the end points of glaucoma, such as visual impairment and visual field constriction, for which reason their robustness and specificity are limited. ${ }^{10}$ There are approximately 18 different patientreported QOL assessments specific to glaucoma. Among these, the Glaucoma Quality of Life-15 Questionnaire (GQL-15) and the Vision and Quality of Life Index have been found most satisfactory in terms of content, validity, and reliability. ${ }^{11}$ Thus, the aim of this study was to investigate the correlations between clinical parameters and glaucoma-specific QOL in Chinese patients with bilateral primary open-angle glaucoma (POAG).

\section{Methods}

For this cross-sectional study, consecutive patients with bilateral POAG were recruited from an academic hospital in Hong Kong. The diagnosis of POAG was based on an open angle on gonioscopy, a presenting IOP of $>21 \mathrm{~mm} \mathrm{Hg}$, and either a glaucomatous visual field loss on at least two Humphrey visual field tracings using the 24-2 SITA fast protocol (Humphrey Instruments, Inc, Zeiss Humphrey, San Leandro [CA], US) or RNFL thinning on Spectralis Optical Coherence Tomography (Heidelberg Engineering, Carlsbad [CA], US). Patients were excluded if they had unilateral disease, concomitant ocular diseases that significantly affected their vision (amblyopia, mature cataract affecting the accuracy of glaucoma investigations). Patients were also excluded if they had other corneal or retinal pathologies, or if they were unable to yield reliable visual field results. Their IOPs were determined using Goldmann applanation tonometry.

The GQL-15 questionnaire is glaucomaspecific, and assesses patient-perceived visual disability in 15 daily tasks responded to in writing. The tasks addressed four aspects of visual disability: (1) central and near vision; (2) peripheral vision; (3) dark adaptation and glare; and (4) outdoor mobility. A 5-point rating scale for the level of difficulty of each task can yield a total score of 0 to 75 . Higher scores signify a lower QOL. The GQL-15 was translated into traditional Chinese text and distributed to participating patients. For illiterate patients, the items were read out to them in Cantonese dialect. The questionnaire was translated from English to Chinese by an investigator who was fluent in both English and Chinese. The translated questionnaire

\section{原發性開角型青光眼的華裔患者中臨床參數和與 青光眼有關的生活質素的關係 \\ 李煒業、陳穎雪、陳焯鴻、李青、黎少明}

目的：探討青光眼的華裔患者中臨床參數和與青光眼有關的生活質素 的關係。

設計：橫斷面研究。

安排 : 香港一所教學醫院。

患者：由連續51名雙側原發性開角型青光眼患者填寫青光眼生活 質素-15問卷量表 (GQL-15) 的中文翻譯版。使用Pearson相關係 數和線性回歸分析, 顯示有數項臨床參數與GQL-15相關。它們包 括從Humphrey視野檢查分析儀得出的青光眼視野指標及模式標準 差、Snellen最佳矯正視力、病發時的眼壓、目前的眼壓、通過光學相 干斷層掃描得出的平均視網膜神經纖維層厚度, 以及外用抗青光眼藥 物的數量

結果：在這些患者中, 較差的GQL-15得分與較低的青光眼視野指標 $\left(r=0.3, r^{2}=0.1, \mathrm{P}=0.01\right)$ 及視力 $\left(r=0.3, r^{2}=0.1, \mathrm{P}=0.03\right)$ 有顯 著相關性和線性關係。較薄的視網膜神經繊維層亦與 GQL-15得分較 差有關, 但未達統計學的顯著相關性 $(r=0.3, \mathrm{P}=0.07)$ 。其他臨床 參數與 GQL-15得分並無統計學上的顯著相關（P值均 $>0.7$ ）。對影 響生活質素最有問題的三項活動是：「對於明亮光線的適應性」 $\ulcorner$ 從光亮的房間走進黑暗的房間, 反之亦然」, 以及「在夜間看東 西」。

結論：對於原發性開角型青光眼的華裔患者, 雙眼的視野指標及視力 跟青光眼有關的生活質素出現線性相關, 而患者最大的問題是參與涉 及黑暗中進行的活動的適應性。

was checked for discrepancies by a second investigator and a consensus was reached to develop a draft Chinese questionnaire. A third investigator then back-translated the draft Chinese questionnaire into English; the back-translated draft and the original version were then compared. Discrepancies were amended and gave rise to the final Chinese version. The questionnaire was then tested on five POAG patients of varying gender and age. Patients were asked to complete the questionnaire, and offer their own interpretation of its contents and whether any alternative wording should be used.

The D'Agostino-Pearson omnibus test was used to test for normality. Nearly half of the parameters passed the normality testing. The means of several clinical parameters were calculated for the two eyes and correlated with the GQL-15 using Pearson's correlation coefficient and linear regression analysis. The selected parameters were the visual field index (VFI) and pattern standard deviation (PSD) from the Humphrey Field Analyzer, the Snellen best-corrected VA, the presenting IOP, current IOP, average RNFL thickness via optical coherence tomography, as well as the number of topical anti-glaucoma medications being used. $t$ Tests were used to test for differences 
between the mean GQL-15 scores between males and females. Data were expressed as mean \pm standard deviation (SD). Any P value of $<0.05$ was accepted as statistically significant.

Our institutional review board granted ethics approval for the study and informed consent was

TABLE. Clinical parameters for both eyes of the patients

\begin{tabular}{lc}
\hline Clinical parameter & Data $^{*}$ \\
\hline Visual field index $(\%)$ & $66.1 \pm 27.5$ \\
\hline Pattern standard deviation $(\mathrm{dB})$ & $6.5 \pm 3.2$ \\
\hline Retinal nerve fibre layer $(\mu \mathrm{m})$ & $64.3 \pm 17.1$ \\
\hline Presenting intra-ocular pressure $(\mathrm{mm} \mathrm{Hg})$ & $24.1 \pm 4.2$ \\
\hline Current intra-ocular pressure $(\mathrm{mm} \mathrm{Hg})$ & $16.3 \pm 3.8$ \\
\hline Snellen visual acuity & $0.6 \pm 0.2$ \\
\hline No. of anti-glaucoma eye drops used & $2.3 \pm 1.0$ \\
\hline
\end{tabular}

* Data are shown as mean \pm standard deviation

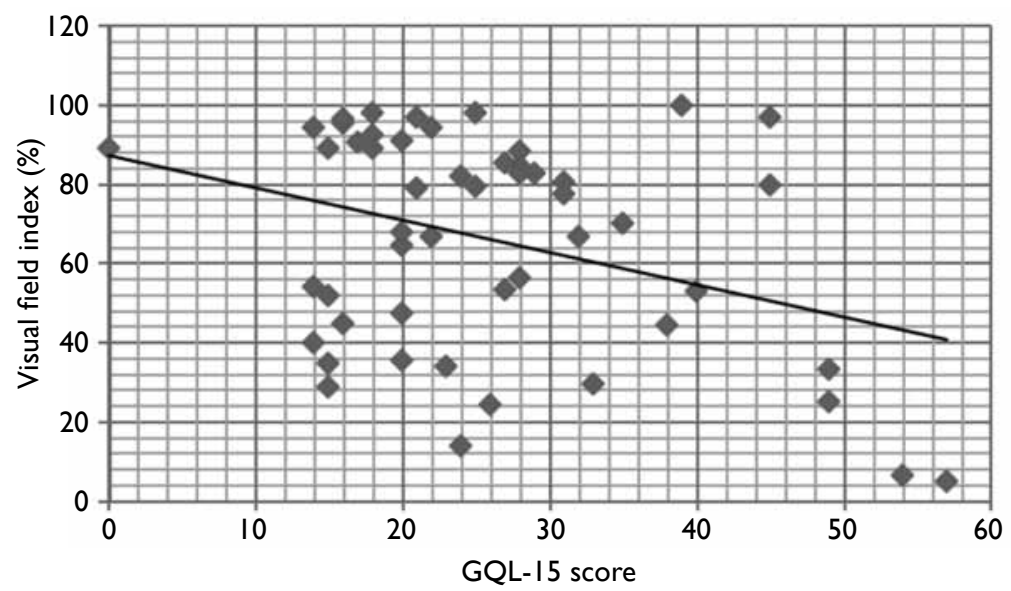

FIG I. Correlation between Glaucoma Quality of Life-15 questionnaire (GQL-I5) and visual field index

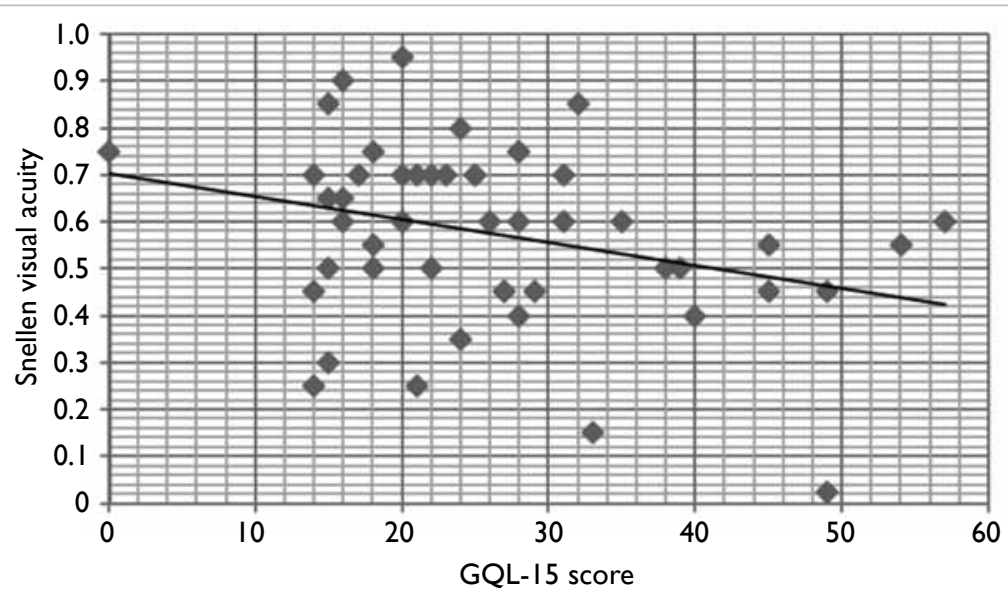

FIG 2. Correlation between Glaucoma Quality of Life-15 questionnaire (GQL-I5) and visual acuity obtained from each patient prior to the start of the study.

\section{Results}

Fifty-one patients with bilateral POAG were recruited, all of whom were Chinese. Their mean $( \pm \mathrm{SD})$ age was $65.8 \pm 12.1$ years and the male-tofemale ratio was 1.1:1.

The means of their clinical parameters for both eyes are shown in the Table. Their mean GQL-15 score was $26.0 \pm 11.6$ (out of 75). The three most problematic activities reported for all patients belonged to: item 4 "adjusting to bright lights" (mean score, $2.3 \pm 1.3$ ); item 6 "going from a light to a dark room or vice versa" (mean score, $2.3 \pm 1.3$ ); and item 2 "seeing at night" (mean score, $2.2 \pm 1.2$ ).

There was a moderately significant correlation between a lower VFI and a poorer GQL-15 score $(r=0.3, \mathrm{P}=0.01$; Fig 1$)$. Likewise, a poorer VA correlated significantly with a poorer GQL-15 score $(r=0.3, \mathrm{P}=0.03$; Fig 2$)$. These two correlations seemed to follow a linear pattern such that linear regression analysis showed a weak linear relationship between a poorer GQL-15 score and a lower VFI $\left(r^{2}=0.1\right.$, $\mathrm{P}=0.01)$ and a poorer VA $\left(r^{2}=0.1, \mathrm{P}=0.03\right)$.

A thinner RNFL appeared to be associated with a poorer GQL-15 score but the correlation did not attain statistical significance $(r=0.3, \mathrm{P}=0.07)$. In terms of pressure control, a higher presenting IOP showed a trend towards correlation with a poorer GQL-15 score $(r=0.2)$ as did a lower current IOP $(r=0.2)$ and a greater number of anti-glaucoma eye drops used $(r=0.1)$. However, none of these correlations reached statistical significance (all $\mathrm{P}>0.7$ ). On comparing GQL-15 scores between male and female glaucoma patients, no significant difference was found $(\mathrm{P}=0.3$, $t$ test).

\section{Discussion}

Various studies have associated QOL with visual field impairment. ${ }^{8,12}$ Odberg et $\mathrm{al}^{13}$ simply categorised visual field defects into "normal", "having a restricted scotoma", or "having a field defect large enough to be of visual significance", and found a weak-to-moderate correlation between such visual field defects and subjective visual disabilities. The Collaborative Initial Glaucoma Treatment Study later found that at the time of diagnosis, patients' visual fields correlated only modestly with a healthrelated QOL questionnaire and that of VFIs; mean deviation (MD) showed better correlation with QOL than PSD, corrected pattern SD, or short-term fluctuation. ${ }^{14}$ Nelson et $\mathrm{al}^{4}$ found that the GQL-15 scores, and especially the subsets pertaining to glare, correlated significantly with MD, even for patients with mild disease. Furthermore, those with moderate and severe visual field loss had 
similar GQL-15 scores, suggesting a threshold for disability may be reached up to a certain level of glaucoma severity ${ }^{4}$ or represent adaptation to loss of visual function. Similarly, Goldberg et $\mathrm{al}^{15}$ have found that the GQL-15 scores correlated with VA, $\mathrm{MD}$, the number of binocular points of $<10 \mathrm{~dB}$, and that QOL tended to decrease with disease severity. Whilst MD is commonly correlated with QOL in glaucoma patients, it has the drawback of not being specific enough to represent the limitations caused by glaucoma alone, since it may also be affected by global defects like cataract. On the other hand, using PSD eliminates the factor of global defects, though it is not sensitive in advanced glaucoma, where the entire field is globally depressed.

Thus in this study, we utilised the VFI, which is a percentage summarising the overall visual field status compared to age-adjusted visual fields. The VFI emphasises the importance of the central field. It is less affected by media opacities (cataracts), and is more accurate than MD for monitoring glaucoma progression. ${ }^{16,17}$ Few studies have usedVFI to correlate with QOL in glaucoma. Sawada et $\mathrm{al}^{18}$ reported that VFI correlated with QOL via the 25-item National Eye Institute Visual Function Questionnaire (NEI VFQ-25) and that the correlation was better than with MD. Our study found a statistically significant correlation between the reduction in mean binocular VFI and a poorer GQL-15 score and that VFI was a better indicator of glaucoma-specific QOL than RNFL thickness, IOP, or PSD on visual field. We chose to use PSD rather than MD in our analysis because the latter could be affected by any global obstruction to vision like cataract, whereas PSD is more specific for inter-field variability. However, the two clinical parameters that achieved a significant correlation with the GQL-15 score were binocular VFI and VA, and both parameters were also associated with the GQL-15 score in a linear manner.

Intra-ocular pressure control did not correlate significantly with QOL although a higher IOP on presentation seemed to produce a lower QOL score, and interestingly a lower current IOP seemed to correlate with a poorer QOL. This unique finding may indicate that those with a lower current IOP have had glaucoma for longer or have more advanced disease warranting more aggressive pressure reduction. Furthermore, those using more anti-glaucoma eye drops seemed to have a lower QOL score, but these correlations were weak and did not reach statistical significance.

Patient perceptions of disease and methods of coping are heavily influenced by culture and ethnicity. Thus, Singapore Chinese glaucoma patients were more accepting of their daily disabilities than corresponding American Caucasians. ${ }^{19}$ Literature pertaining to Chinese glaucoma patients is sparse. $\mathrm{Wu}$ et $\mathrm{al}^{20}$ found that Chinese glaucoma patients were particularly concerned about the uncertainties of treatment, the prognosis, and passing on of the disease to family members. Lin and Yang ${ }^{21}$ reported a correlation with MD and the Medical Outcomes Study Short-Form 36 Health Survey and the NEI VFQ-25. Whilst clinical data provide evidence of structural and functional damage of the optic nerve, they do not address the impact of disease on patients. The correlation of objective clinical measurements to QOL is particularly useful, because it gives ophthalmologists in a busy clinical setting an overall impression of glaucoma-specific QOL. This can enable them to recommend environmental and lifestyle modifications to minimise obstacles and maximise the period of independence. ${ }^{5}$ Our study found that in Chinese glaucoma patients, the most problematic aspects of coping were "adjusting to bright lights", "going from a light to a dark room or vice versa", and "seeing at night". Interestingly, all these activities belong to the realm of dark adaptation. Hence, environmental modifications can potentially help to reduce glare. ${ }^{4}$ Furthermore, an estimation of QOL from clinical parameters can allow ophthalmologists to more readily identify patients with a poorer QOL needing more psychosocial support. Interestingly, it has been reported that POAG itself is associated with anxiety, depression, and hypochrondriasis ${ }^{22}$ and a low GQL-15 score has also been identified as a predictor for depression. ${ }^{23}$

One limitation of our study was that it was cross-sectional and looked at POAG patients with varying degrees of severity. A longitudinal study would have provided additional information about the changes in QOL throughout different stages of the disease. A second limitation was that the population received heterogeneous treatments (lasers and surgeries). However, as the aim of this study did not involve evaluating the side-effects of glaucoma treatments and since the GQL-15 too did not target treatment side-effects, we did not consider it necessary to exclude those who had undergone such treatments previously. Rather, we opted to include a more heterogeneous POAG population to make the results more generalisable and representative. A third limitation was that no single test is perfect; the GQL-15 mainly focuses on visual activities, which is only one aspect of QOL. Conceivably, such a questionnaire only reflects patient confidence to perform certain tasks rather than the actual difficulties experienced. Nevertheless, it has been shown that patients' loss of confidence often precedes their perceptions of difficulty. ${ }^{24}$

To the best of our knowledge, this is one of the few studies reporting a significant correlation and a linear relationship between VFI and the glaucomaspecific GQL-15 score in the Chinese POAG patients. This study also identified dark adaptation as the most challenging visual issue pertinent to 
Chinese POAG patients.

\section{Declaration}

No conflicts of interest were declared by the authors.

\section{References}

1. Mansberger SL, Demirel S. Early detection of glaucomatous visual field loss: why, what, where, and how. Ophthalmol Clin North Am 2005;18:365-73, v-vi.

2. Beauchamp CL, Beauchamp GR, Stager DR Sr, Brown MM, Brown GC, Felius J. The cost utility of strabismus surgery in adults. J AAPOS 2006;10:394-9.

3. Brown GC, Brown MM, Sharma S, et al. The burden of age-related macular degeneration: a value-based medicine analysis. Trans Am Ophthalmol Soc 2005;103:173-86.

4. Nelson P, Aspinall P, Papasouliotis O, Worton B, O'Brien C. Quality of life in glaucoma and its relationship with visual function. J Glaucoma 2003;12:139-50.

5. Spaeth G, Walt J, Keener J. Evaluation of quality of life for patients with glaucoma. Am J Ophthalmol 2006;141(1 Suppl):S3-14.

6. Jampel HD, Schwartz A, Pollack I, Abrams D, Weiss H, Miller R. Glaucoma patients' assessment of their visual function and quality of life. J Glaucoma 2002;11:154-63.

7. Janz NK, Wren PA, Lichter PR, Musch DC, Gillespie BW, Guire KE. Quality of life in newly diagnosed glaucoma patients: the Collaborative Initial Glaucoma Treatment Study. Ophthalmology 2002;108:887-97; discussion 898

8. Parrish RK 2nd, Gedde SJ, Scott IU, et al. Visual function and quality of life among patients with glaucoma. Arch Ophthalmol 1997;115:1447-55.

9. Gutierrez P, Wilson MR, Johnson C, et al. Influence of glaucomatous visual field loss on health-related quality of life. Arch Ophthalmol 1997;115:777-84.

10. Mills T, Law SK, Walt J, Buchholz P, Hansen J. Quality of life in glaucoma and three other chronic diseases: a systematic literature review. Drugs Aging 2009;26:933-50.

11. Vandenbroeck S, De Geest S, Zeyen T, Stalmans I, Dobbels F. Patient-reported outcomes (PRO's) in glaucoma: a systematic review. Eye (Lond) 2011;25:555-77.

12. Lee BL, Gutierrez P, Gordon M, et al. The Glaucoma Symptom Scale. A brief index of glaucoma-specific symptoms. Arch Ophthalmol 1998;16:861-6.
13. Odberg T, Jakobsen JE, Hultgren SJ, Halseide R. The impact of glaucoma on the quality of life of patients in Norway. II. Patient response correlated to objective data. Acta Ophthalmol Scand 2001;79:121-4.

14. Mills RP, Janz NK, Wren PA, Guire KE. Correlation of visual field with quality-of-life measures at diagnosis in the Collaborative Initial Glaucoma Treatment Study (CIGTS). J Glaucoma 2001;10:192-8.

15. Goldberg I, Clement CI, Chiang TH, et al. Assessing quality of life in patients with glaucoma using the Glaucoma Quality of Life-15 (GQL-15) questionnaire. J Glaucoma 2009;18:6-12.

16. Bengtsson B, Heijl A. A visual field index for calculation of glaucoma rate of progression. Am J Ophthalmol 2008;145:343-53.

17. Casas-Llera P, Rebolleda G, Muñoz-Negrete FJ, ArnalichMontiel F, Pérez-López M, Fernández-Buenaga R. Visual field index rate and event-based glaucoma progression analysis: comparison in a glaucoma population. $\mathrm{Br} \mathrm{J}$ Ophthalmol 2009;93:1576-9.

18. Sawada H, Fukuchi T, Abe H. Evaluation of the relationship between quality of vision and the visual function index in Japanese glaucoma patients. Graefes Arch Clin Exp Ophthalmol 2011;249:1721-7.

19. Saw SM, Gazzard G, Au Eong KG, Oen F, Seah S. Utility values in Singapore Chinese adults with primary openangle and primary angle-closure glaucoma. J Glaucoma 2005;14:455-62.

20. Wu PX, Guo WY, Xia HO, Lu HJ, Xi SX. Patients' experience of living with glaucoma: a phenomenological study. J Adv Nurs 2011;67:800-10.

21. Lin JC, Yang MC. Correlation of visual function with health-related quality of life in glaucoma patients. J Eval Clin Pract 2010;16:134-40.

22. Erb C, Thiel HJ, Flammer J. The psychology of the glaucoma patient. Curr Opin Ophthalmol 1998;9:65-70.

23. Skalicky S, Goldberg I. Depression and quality of life in patients with glaucoma: a cross-sectional analysis using the Geriatric Depression Scale-15, assessment of function related to vision, and the Glaucoma Quality of Life-15. J Glaucoma 2008;17:546-51.

24. Nelson P, Aspinall P, O'Brien C. Patients' perception of visual impairment in glaucoma: a pilot study. $\mathrm{Br} \mathrm{J}$ Ophthalmol 1999;83:546-52. 